\title{
Preference for the Outcome That Follows a Relatively Aversive Event: Contrast or Delay Reduction?
}

\author{
Rebecca A. Singer and \\ Department of Psychology, Georgetown College, Georgetown, KY 40324, Phone: 502-863-8353, \\ Rebecca_Singer@georgetowncollege.edu \\ Thomas R. Zentall \\ Department of Psychology, University of Kentucky, Lexington, KY 40506-0044. zentall@uky.edu
}

\begin{abstract}
Pigeons prefer a positive discriminative ( $\mathrm{S}+$ ) stimulus that follows a less preferred event (a large number of required responses, a longer delay, or the absence of food) over a different $\mathrm{S}+$ with a similar history of reinforcement that follows a more preferred event (a single required response, no delay, or food). We proposed that this phenomenon results from contrast (referred to as withintrial contrast) between the less preferred initial event and the signal for reinforcement. Delay reduction theory (Fantino, 1969) can account for these results by proposing that the less preferred initial event lengthens the duration of the trial, thereby allowing the $\mathrm{S}+$ stimulus to occur later in the trial and thus become a better predictor of reinforcement. In the present experiments, we further explored this effect. In Experiment 1, we controlled for trial duration by using a fixed ratio response (30 pecks) as one initial event and the absence of pecking for the same duration as the other initial event ( 0 pecks). The pigeons showed a reliable preference for the positive stimulus that followed the least preferred initial event. In Experiment 2, we controlled for trial duration by using 30 pecks as one initial event and 1 peck followed by a delay that matched the duration of the preceding 30-peck trial. (Group Time Same). For Group Time Different, there was no delay following the 1-peck initial event. For Group Time Same, preference for the initial event negatively predicted the pigeons' preference for the S+ stimulus that followed, supporting the contrast account. A somewhat greater preference for the discriminative stimulus that followed the least preferred initial event was found for Group Time Different suggesting that in addition to contrast, delay reduction also may play a small role. However, the greater initial-event preference found for Group Time Different suggests that contrast can account for the group difference as well.
\end{abstract}

\section{Keywords}

contrast; delay reduction; justification of effort; reinforcement value; choice; pigeons

When pigeons are required to expend more effort (peck 20 times) on some trials but not on others (peck only once), they often show a preference for the discriminative stimulus that follows the greater peck requirement (Clement, Feltus, Kaiser, \& Zentall, 2000). Based on

\footnotetext{
(C) 2011 Elsevier Inc. All rights reserved.

Correspondence to: Rebecca A. Singer; Thomas R. Zentall.
}

Publisher's Disclaimer: This is a PDF file of an unedited manuscript that has been accepted for publication. As a service to our customers we are providing this early version of the manuscript. The manuscript will undergo copyediting, typesetting, and review of the resulting proof before it is published in its final citable form. Please note that during the production process errors may be discovered which could affect the content, and all legal disclaimers that apply to the journal pertain. 
traditional theories of learning (e.g., Hull, 1943; Spence, 1937), discriminative stimulus preference should be determined not by the antecedent conditions but by the consequent conditions (the effort required to obtain the outcome, the delay to obtain the outcome, and the magnitude of the reinforcer). When these events are held constant, no consistent preference should be seen.

Alternatively, the pigeons might develop a backward association between the discriminative stimulus and the preceding response (Spetch, Wilkie, \& Pinel, 1981) or one could think of this as a procedure that involves a 'good' context in which a single peck is sufficient to produce the stimulus associated with reinforcement and a 'bad' context in which it takes 20 pecks to produce the stimulus associated with reinforcement. According to either the backward association or context view, on test trials, pigeons should prefer the discriminative stimulus that followed the low effort response.

Finally, it is possible that pigeons would prefer the discriminative stimulus depending on the effort that preceded the test trial. That is, they might respond conditionally depending on the nature of the test trial.

Surprisingly, the pigeons in the Clement et al. (2000) experiment preferred the discriminative stimuli that followed the least preferred initial event. Clement et al. explained this effect as a form of contrast that they referred to as within-trial contrast. According to this account, the value of the discriminative stimulus should depend on the relative value of the outcome (or in this case the $\mathrm{S}+$ stimulus that signals the outcome). High effort is generally assumed to be relatively more aversive than low effort. Thus, a greater improvement in value should occur when the S+ stimulus appears following greater effort than following less effort (see Figure 1).

A similar within-trial contrast effect has been found in starlings. Kacelnik and Marsh (2002) trained starlings to peck one color following high effort trials (16 1-m flights between two perches) and a different color following low effort trials (four 1-m flights between two perches). On test trials, the starlings were given a choice between the two colors. As in the Clement et al. (2000) study, significantly more subjects chose the color that followed high effort flights than the color that followed low effort flights. According to the contrast hypothesis, the more flights a starling has to make, the greater should be the value of the colored light associated with the outcome.

There is also evidence that pigeons' preference between two equally reinforcing feeders (one on the left the other on the right) shifts significantly toward the originally nonpreferred feeder if reinforcement from the nonpreferred feeder requires 30 key pecks to obtain, whereas reinforcement from the preferred feeder requires only 1 key peck to obtain (Friedrich \& Zentall, 2004). And recently, Johnson and Gallagher (2011) found that mice that worked for comparably preferred solutions of sucrose and polycose increased their later intake of the solution that they had to work harder to obtain (15 lever presses to obtain the solution) relative to the solution that was easier to obtain (one lever press to obtain the solution).

The contrast hypothesis, as depicted in Figure 1, is based on the assumption that any relatively aversive event that precedes the outcome will result in a preference for that outcome (or for the positive, S+, stimulus that precedes it) over the outcome following a less aversive event. For example, contrast should be found when an S+ stimulus follows a longer rather than a shorter delay or when the prior event is the absence of food rather than the presence of food. These predictions are counterintuitive because they predict that something relatively aversive will produce a preference for the stimulus that follows. 
DiGian, Friedrich, and Zentall (2004) tested the first prediction involving differential delays. Consistent with the contrast account, the pigeons preferred the discriminative stimulus that followed a delay in training over the discriminative stimulus that followed no delay. Friedrich, Clement, and Zentall (2005) tested the second prediction involving food versus absence of food as the prior event. Pigeons pecked for food on some trials and the absence of food on others. Food was followed by one S+ stimulus, the absence of food by another. In either case, food followed choice of the S+ stimulus (as well). On test trials, when the pigeons were given a choice between the two S+ stimuli, they reliably preferred the one that had followed the absence of food over the one that had followed food. Thus, a nonpreferred event (in this case the absence of food) appears to have produced a preference for the S+ stimulus that follows.

There is also evidence that the level of deprivation at the time of testing can serve as a relatively aversive event. Marsh, Schuck-Paim, and Kacelnik (2004) trained European starlings to peck a lit response key that was one color (e.g., red) on trials when they were prefed and another color (e.g., green) on trials when they were not prefed. On test trials, when they were given a choice between the red and green colors, they showed a significant preference for the color that in training was associated with the absence of prefeeding (viz., hunger). Furthermore, this preference was unaffected by whether they were prefed or not at the time of testing (see also Pompilio, Kacelnik, \& Behmer, 2006; Revusky, 1967;

Vasconcelos, \& Urcuioli, 2008).

Although the contrast interpretation is consistent with these findings, an alternative hypothesis can make similar predictions (Fantino, 1969). Fantino argued that any stimulus that is associated with a reduction in the delay to reinforcement should become a conditioned reinforcer or conditional appetitive stimulus. Although in the experiments described here, the absolute delay to reinforcement associated with the two discriminative stimuli was always equal, the relative delay to reinforcement generally was not. If one considers the trial as a whole, the discriminative stimulus comes closer to the outcome as a proportion of the trial duration when the pecking requirement is high than when it is low (Fantino \& Abarca, 1985). If one considers the relative delay to reinforcement, other theories such as Mazur's (2001) hyperbolic value added model and Grace's (1994) contextual-choice model also make the same prediction.

Relative delay reduction can also account for the results of the delay manipulation (DiGian et al., 2004). The longer the delay prior to the onset of the S+ stimulus, the relatively closer the discriminative stimulus would come to the outcome and thus, the better conditioning would be.

How delay reduction theory can account for the results of the manipulation of reinforcement as the initial stimulus may not be obvious because the trial durations were held constant. But according to delay reduction theory, what is critical is the time between reinforcements. If so, on trials with reinforcement provided prior to the S+ stimulus, the interval between reinforcers would be short and the $\mathrm{S}+$ stimulus would not result in a large reduction in the delay to reinforcement. On the other hand, on trials with the absence of reinforcement provided prior to the discriminative stimulus, the interval between reinforcers would be quite a bit longer because the last reinforcer presumably would have come at the end of the previous trial and the appearance of the discriminative stimulus should thus result in a relatively greater reduction in the delay to reinforcement. A similar argument can be made for the results of experiments involving prefeeding (Marsh et al., 2004: Pompilio et al, 2006; Revusky, 1967; Vasconcelos, \& Urcuioli, 2008), as long as one considers the time between the last feeding and the signal for reinforcement as the basis for judgments of delay reduction. 
Singer, Berry, and Zentall (2007) attempted to distinguish between delay reduction and contrast by equating the duration of the two kinds of trial as well as time between trials. They accomplished this by using a fixed interval (FI) schedule of reinforcement as the initial event on half of the trials and an equal duration, differential reinforcement of other behavior (DRO) schedule of reinforcement (the absence of pecking for a specified time) on the others. Singer et al. first tested each pigeon for its schedule preference and because there were individual differences, they used the preference of each pigeon to define the less preferred initial event. Then after following each schedule by a simultaneous discrimination using the Clement et al. (2000) procedure, on test trials, not only did the pigeons show a preference for the S+ stimulus that followed the less preferred initial schedule but there was also a significant (negative) correlation between the degree of schedule preference and the preference for the discriminative stimulus that followed. Thus, the results provided support for the within-trial contrast account.

The purpose of the current experiments was to confirm and extend the results of Singer et al. (2007) and demonstrate that within-trial contrast can occur under conditions that control for the duration of the S+ relative to the total duration of the trials or the time between reinforcements. In the first experiment, we increased the response requirement on some of the trials by using a fixed ratio schedule rather than the fixed interval schedule and we compared the effect of the initial fixed interval initial event with that of an initial DRO event. To ensure equal durations for the two kinds of trial, we equated trial durations on a trial by trial basis. Following initial schedule training, we determined which schedule each pigeon preferred and then followed each schedule with a different simultaneous discrimination. Finally, on test trials, we gave the pigeons a choice between the two S+ stimuli.

In the second experiment we used differential initial events similar to those used by Clement et al. (2000), 1 versus 30 pecks, but we equated the trials for their duration. We accomplished this by using the time to complete the 30 peck initial event requirement on each trial to determine the delay that would follow the 1 peck requirement on the next trial. Once again, following initial schedule training, we determined the schedule preference for each pigeon and then followed each schedule with a different simultaneous discrimination. On test trials, we gave the pigeons a choice between the two positive discriminative stimuli. Once again, if pigeons prefer the $\mathrm{S}+$ stimulus that follows their least preferred schedule, the results would not be predicted by delay reduction theory.

In both experiments we followed the initial event with a simultaneous discrimination involving a positive stimulus ( $\mathrm{S}+$ ) choice of which was reinforced and a negative stimulus (S-) choice of which was not. We also tested the pigeons for their choice between the two Sstimuli. In this case, although neither theory makes a specific prediction, Clement et al. (2000) also found a preference for the S- stimulus that followed the least preferred schedule and they explained this preference as a form of generalization referred to as value transfer (see Zentall \& Sherburne, 1994). However, in many experiments on within-trial contrast, little evidence of a differential preference for the negative stimuli has been found (see Clement et al., 2000; DiGian et al., 2004; Friedrich et al., 2005; Friedrich \& Zentall, 2004).

\section{Experiment 1}

In Experiment 1 we first asked whether pigeons preferred a fixed ratio schedule of reinforcement, a differential reinforcement of other behavior (DRO) schedule of the same duration, or neither. The contrast hypothesis makes no prediction about schedule preferences with this procedure because schedule preference is an empirical question; however, if there 
are schedule or side preferences, the contrast hypothesis predicts that there will be a preference for discriminative stimuli that follow the less preferred schedule or side.

\section{Method}

Subjects-The subjects were 8 White Carneaux pigeons (Columba livia), retired breeders (5-8 years of age) of undetermined sex, purchased from the Palmetto Pigeon Plant (Sumter, SC). The pigeons were individually housed in wire cages and maintained at $85 \%$ of their free-feeding body weight for the duration of the experiment. The pigeons had free access to water and grit in their home cage. The pigeon colony room was maintained on a 12:12-hr light-dark cycle. The pigeons were cared for in accordance with University of Kentucky animal care guidelines. All pigeons had previous experience in unrelated studies involving two-sample, two-alternative, matching-to-sample (conditional discriminations).

Apparatus-The experiment was conducted in a standard operant chamber (BRS/LVE, Laurel, MD). The operant chamber measured $32.0 \mathrm{~cm}$ high, $32.0 \mathrm{~cm}$ across the response panel, and $28.0 \mathrm{~cm}$ from the response panel to the back wall. Three square response keys $(2.5 \times 2.5 \mathrm{~cm})$ were aligned horizontally on the response panel and were separated by 0.8 $\mathrm{cm}$. A 12-stimulus in-line projector (Industrial Electronics Engineering, Van Nuys, CA) with $28 \mathrm{~V}, 0.1 \mathrm{~A}$ lamps (no. 1820) was mounted behind each response key. The two side keys projected a white (unfiltered) stimulus. The center key projected three white parallel lines against a black background arranged either horizontally $(\mathrm{H})$ or vertically $(\mathrm{V})$. The three lines were $2.0 \mathrm{~mm}$ apart and each was $2.0 \mathrm{~mm}$ wide and $2.5 \mathrm{~cm}$ long. An unfiltered houselight (no. 1820) mounted in the center of the ceiling illuminated the intertrial intervals. A rear-mounted feeder on the response panel provided mixed grain reinforcement (Purina Pro Grains) through a $5.1 \mathrm{~cm} \times 5.5 \mathrm{~cm}$ aperture centered horizontally on the response panel and vertically midway between the response keys and the floor of the chamber.

Reinforcement consisted of $1.5 \mathrm{~s}$ access to the mixed grain. An exhaust fan was mounted outside the chamber to mask extraneous noise. The experiment was controlled and data collected by a microcomputer located in an adjacent room.

\section{Procedure}

Schedule Preference Training: Pigeons were trained with two schedules of reinforcement. Each schedule was initiated by a white light on the left or the right side key. A single peck to the white light turned it off and turned on vertical or horizontal lines on the center key. For half of the pigeons, the fixed ratio, 20 peck (FR20) schedule was signaled by the white key on the right followed by vertical lines on the center (which will be referred to as FR initiated trials) and the DRO schedule was signaled by a white key on the left followed by horizontal lines on the center (which will be referred to as DRO initiated trials). The duration of the DRO schedule was determined by the time it took to complete the pecking requirement on the previous FR trial. FR and DRO trials were alternated. Pecks to the horizontal stimulus during the DRO schedule reset the timer. Completion of the schedule on the center key led to reinforcement. Each trial was followed by a 10-s intertrial interval illuminated by the houselight. The contingencies signaled by the side keys were reversed for the remaining pigeons. Each session consisted of 72 trials, 36 FR trials alternating with 36 DRO trials. Training sessions were conducted once a day, 6 days a week.

Pigeons remained in schedule training until there were no DRO pecks for two consecutive sessions. After reaching criterion, the pigeons received 5 sessions of overtraining intended to ensure stability of responding on the two schedules.

Schedule Preference Testing 1: Testing sessions involved 18 test trials in which the pigeon was given a choice between the left and right white side keys. Whichever key was chosen 
determined the FR20 or DRO schedule that followed. These test trials were interspersed among 54 training trials. Pigeons remained in schedule preference testing for a minimum of 10 testing sessions. If after 10 sessions, the pigeon had showed a preference for one of the schedules of $90 \%$ or greater, it was moved to the second testing phase. If the pigeon did not have a $90 \%$ preference after 10 testing sessions, it remained in the schedule preference testing phase until it had reached a stability criterion of 4 consecutive sessions in which the range of preference did not vary by more than $20 \%$.

Schedule Preference Testing 2 (reversal testing): To distinguish between a side key preference and a schedule preference, the schedule associated with each side key was reversed following Schedule Preference Testing 1. The horizontal and vertical line stimuli continued to signal the same schedule of reinforcement as they did during original training and Schedule Preference Testing 1.

According to the contrast hypothesis, it should not matter whether the basis of the preference for the initial event was one of the schedules or one of the side keys. The contrast hypothesis would predict a preference for the positive stimulus that followed the least preferred initial event, whether it was one of the two schedules or one of the two sides.

Pigeons remained in reversal testing until they showed a preference for one of the schedules at a level of $90 \%$ or greater or they had achieved a stability criterion of 4 consecutive sessions in which the range of preference did not vary by more than $20 \%$. Each session consisted of 72 trials (54 training trials and 18 test trials).

Discrimination Training: For each pigeon, the side key associated with each schedule was the same as it was at the end of schedule preference testing. During discrimination training, completion of each of the schedules was followed by presentation of a pair of discriminative stimuli on the side keys. Each schedule was associated with a different pair of discriminative stimuli. For example, if the right key initiated the trial, pecking it was followed by presentation of the vertical line stimulus that signaled that the FR schedule of reinforcement was in effect. Twenty pecks to the center stimulus was followed by presentation of a pair of discriminative stimuli (e.g., green+ blue-) and choice of the positive stimulus (i.e., green) was reinforced. If the left side key was illuminated, pecking it was followed by the horizontal line stimulus on the center key. The horizontal line stimulus signaled that a DRO schedule of reinforcement was in effect. After a duration determined by the previous FR trial had elapsed with no pecking, the pigeon was presented with a different pair of discriminative stimuli (e.g., red+ yellow-) and choice of the positive stimulus (i.e., red) was reinforced. For half of the pigeons, red and yellow stimuli followed the DRO trials and green and blue stimuli followed the FR trials (see Figure 2). For the remaining pigeons, red and yellow stimuli followed the FR trials and green and blue stimuli followed the DRO trials. The location of the two pairs of colors was counterbalanced over trials.

Each session consisted of 84 trials; 80 of which were training trials, 40 DRO initiated trials and 40 FR initiated trials. The remaining 4 trials were choice trials on which the two white side keys were presented simultaneously and the pigeons were given a choice between the two schedules of reinforcement. Pigeons remained in training until they reached a criterion of $90 \%$ correct on both of the simultaneous discriminations for 2 consecutive sessions.

Stimulus Preference Testing: Each of six testing sessions consisted of the discrimination training trials, as well as test trials in which the two positive stimuli (e.g., red and green) or the two negative stimuli (e.g., yellow and blue) were presented on the side keys. Each of these novel combinations of stimuli appeared equally often after a DRO event, an FR event, 
or no event (test stimuli appeared immediately after the intertrial interval). Choice on these test trials was reinforced non-differentially, $50 \%$ of the time.

Each test session consisted of 80 trials. There were 32 training trials, as described above. The remaining 48 trials were test trials with 24 positive stimulus test trials (pigeons were given a choice between the two positive stimuli) and 24 negative stimulus test trials, 8 of these each initiated by a FR schedule, a DRO schedule, or no schedule (see Figure 3). Some test trials were preceded by an FR schedule and some by a DRO schedule to test for the possibility that the prior schedule provided a contextual or conditional cue for choice of the positive or negative stimulus. Thus, although the pigeons may not show an overall preference for either positive or negative stimulus, they may choose the positive or negative stimulus according to which schedule in training preceded it. On the remaining test trials there was no prior schedule. These trials were included to provide a test that was relatively free of differential training context. The test trials were randomly ordered, and the two test stimuli were counterbalanced for the side key on which they appeared. The first test session was administered the day after each pigeon reached the training criterion. Each of the remaining six test sessions was preceded by 10 additional training sessions. These additional training sessions were conducted because it was not possible to independently assess the association of the training schedule (FR or DRO) with the discriminative stimuli that followed and earlier research suggested that 20-50 sessions of training were needed to produce a clear stimulus preference (see Friedrich \& Zentall, 2004; Singer et al., 2007).

\section{Results}

Acquisition-One pigeon became ill before schedule preference testing and had to be removed from the study for treatment. The remaining 7 pigeons reached the schedule preference criterion in an average of 44.5 sessions $(S E M=11.23)$. Within five sessions of training, the pigeons stopped responding on the DRO schedule and most of the responding occurred during the first session.

Schedule Preference-The last 4 sessions from Testing Phase 1 and the last 4 sessions from Testing Phase 2 (reversal testing) were used to calculate schedule (and side key) preferences. For each pigeon, preference was defined by a choice score that was significantly different from chance (see Table 1). Overall, the pigeons showed no systematic schedule preference. Some of the pigeons had a strong schedule preference, whereas others showed a strong side preference (they did not switch their side preference when the schedule signaled by the side key switched).

As indicated by a Fisher's exact test performed on the data from each pigeon, 4 of the 7 pigeons showed a significant schedule preference, 3 for the DRO and 1 for the FR schedule. The remaining 3 pigeons showed a stronger side preference than schedule preference and these side preferences were also significantly greater than chance. A schedule or side preference was considered strong if the difference between the side and schedule preference score was greater than $15 \%$. All 7 pigeons demonstrated strong preferences.

Discrimination Training-One of the seven pigeons died during the testing phase and its data were dropped from the study. All of the remaining pigeons reached criterion on discrimination training within 4 sessions.

Stimulus Preference Testing-For the first test session, a schedule (or side) preference score was obtained from the last 4 sessions of schedule preference testing as well as the preference scores from discrimination training. For Test Sessions 2 through 6, the schedule 
preference score was calculated from the mean preference scores from the preceding 10 sessions of discrimination training.

S+ Preference Test: On Tests 1, 2, 3, and 4, the positive (S+) stimulus preference was small $(M=55.2, S E M=4.63, M=53.6, S E M=7.41, M=53.5, S E M=8.15$ and $M=55.6, S E M$ $=8.10$, respectively) and not significantly different from chance (see Figure 4 ) as indicated by a single sample two-tailed $t$-test (all $t$ s $<1$ except on Test 1 for which $t(5)=1.08$ ). The magnitude of the effect remained small until Test 5 . On Test 5 , a significant preference $(M=$ $63.90, S E M=5.34$ ) was found for the $\mathrm{S}+$ that followed the non-preferred schedule in training, $t(5)=2.60, p<.05$. The preference for the $\mathrm{S}+$ that followed the non-preferred schedule in training remained stable on Test $6(M=63.89, S E M=4.39)$ and was also significantly different from chance, $t(5)=3.16, p<.05$.

A strong test of within-trial contrast can be obtained by examining the correlation between the schedule preference and the magnitude of the S+ preference that followed it in training. A product-moment correlation performed on those data indicated the correlation was not statistically significant, $r=-.60, t=1.5, p>.05$. Although the negative correlation was quite high, with only six subjects, the test had little power so it is not surprising that the correlation was not statistically reliable. Furthermore, four of the six pigeons showed very strong schedule preferences (> 90\%) so there was relatively little variability in the magnitude of the schedule preference.

S- Preference Test: Similar stimulus preference tests were conducted for the S- stimuli. They indicated that the negative stimulus associated with the non-preferred schedule (or side) was not significantly preferred on any of the six test sessions (all $t \mathrm{~s}<1$ ). As can be seen in Figure 4, the greatest preference for the non-preferred S- occurred early in the testing phase and steadily decreased over test sessions. Also, as can be seen in Figure 4 there was great variability among the pigeon's preference for the S- stimuli.

Interestingly, a product-moment correlation performed on the schedule preference scores and the magnitude of the S- preference that followed it in training indicated that there was a significant positive correlation, $r=.828, t=2.95, p=.04$. Thus, in this case, the greater the schedule preference, the greater was the preference for the S- stimulus that followed (or the more the pigeons avoided the S- stimulus that followed the more preferred schedule; see Arantes \& Grace, 2008).

Effect of Initial Event on Test Trials-Because it is possible that on test trials the pigeons may choose the discriminative stimulus conditionally based on the initial event that preceded it on that test trial, each test session was analyzed for choice of the FR (S+ and S-) stimuli preceded by the FR20, DRO, or no initial event. There was no significant effect of the initial event on test trials on the $\mathrm{S}+$ preference pooled over all test sessions, $F(2,15)=$ $2.46, p>.05$. Figure 5 shows the effect of initial event on choice of the $\mathrm{S}+$ associated with the FR schedule. However, there was a significant effect of initial stimulus on the Spreference pooled over all test sessions, $F(2,15)=5.60, p<.05$. Figure 5 shows that the pigeons chose the S- stimulus associated with the FR schedule more often after DRO test trials than after FR test trials or no schedule test trials. When trials involving only the initial events experienced during training were considered (FR20 and DRO), the effect of the initial event on test trials on the $\mathrm{S}+$ preference pooled over all test sessions, was statistically significant, $t(5)=3.62, p=.02$. This result suggests that on test trials, the pigeons were using the initial stimulus as a partial conditional cue. When the same analysis was performed on the data from S- test trials, the difference was statistically significant as well, $t(5)=7.12$, $p=.0021$; however, in this case it appears that the pigeons were using the initial event as a conditional cue to avoid the S- stimulus. 


\section{Discussion}

Large individual differences in schedule preference were found in Experiment 1. Three of the seven pigeons showed a preference for the DRO schedule and one pigeon preferred the FR schedule. The preference for the FR schedule may be attributable to the fact that on the FR trials, the delay to reinforcement is an inverse function of response rate. Thus, the pigeon had some control over how long it took to earn reinforcement on FR trials, but only indirect control over the delay to reinforcement on the DRO trials as the duration of those trials in the absence of pecking depended on the rate of pecking on the preceding FR trial. The remaining three pigeons preferred one of the side keys (i.e., they did not switch sides when the schedules switched sides).

Results from Experiment 1 were consistent with the contrast hypothesis. The pigeons demonstrated a significant preference for the positive stimulus associated with their nonpreferred schedule (or side). However, given that an attempt was made to carefully control the duration of the two kinds of trial, it is not clear how delay reduction theory would account for these results.

It is important to note that significant contrast effects were slow to develop. The preference for the non-preferred positive stimulus rose sharply on the fifth test session and remained stable on the sixth test session. Although the pigeons acquired the simultaneous discriminations quickly, apparently it took considerably longer for them to associate those colors with the event that preceded them.

No corresponding significant preference for the negative stimulus associated with the nonpreferred schedule or side was found. Negative stimulus preferences resulting from the prior schedule typically have been quite variable. Although Clement et al. (2000) found such an effect and it was consistent with the preferences found for the positive stimuli, other studies have also failed to find a contrast effect when the negative stimuli were tested (see e.g., DiGian et al., 2004 and Friedrich et al., 2005). In addition, Klein et al. (2005) examined within-trial contrast in humans and found significant preference for the positive stimulus associated with the least preferred prior schedule but there was no corresponding preference for the negative stimulus. It is possible that the variability in results for the negative stimulus can be attributed to the fact that typically the pigeons have little experience with the outcome associated with choosing the negative stimuli because the pigeons quickly meet a criterion of $90 \%$ or better on both discriminations to move to testing and as testing continued, the pigeons rarely choose the incorrect discriminative stimulus in training and therefore for many sessions they had had little or no experience with the consequence of choosing them.

The presence of a significant effect of the initial event on test trials involving the two positive stimuli has been reported earlier (Friedrich et al, 2005, and DiGian, et al., 2004, found an effect in the same direction but it was not significant). It should be noted that the preference for the $\mathrm{S}+$ that followed the less preferred initial event experienced during training did not depend on the initial event on test trials.

The significant effect of the initial event on test trials involving the two negative stimuli found in the present experiment is not a typical finding. It may be that the absence of an overall preference for one of the negative stimuli, as was found in the present experiment, permitted the appearance of an effect of the initial event on test trials. It should be noted, however, that the greater preference for the negative stimulus that followed the FR schedule occurred on test trials on which the initial event was the DRO schedule. Thus, it appears that the initial event may have served as a conditional cue to avoid the S- stimulus that followed. 


\section{Experiment 2}

The procedure used by Singer at al. (2007) equated trial duration by requiring that the pigeons refrain from pecking when the discriminative stimulus associated with the DRO schedule was presented. Although the DRO requirement nominally controls for the trial duration, in practice, it is difficult to control for both time to complete the FR and time to complete the DRO, especially during early sessions when pecks occasionally occurred to the DRO stimulus. A more precise way to equate for trial duration while manipulating possible relative aversiveness of the initial link is to return to the FR1 versus FR30 manipulation but insert a delay after the FR1 requirement equal to the time it takes to complete the FR30 response. Thus, the purpose of Experiment 2 was to test the contrast account while equating more precisely for the total duration of the trial.

When given a choice, pigeons show a strong preference for pecking once, over pecking 30 times (Friedrich et al., 2004), but if trial duration is equated, they may not prefer an FR1 initial event followed by a delay over a comparable duration FR30 trial. Vasconcelos, Urcuioli, and Lionello-DeNolf (2007) used a similar procedure in which trial duration was equated, and they failed to observe a contrast effect, but, as we explain later, they may not have provided sufficient training to allow contrast to develop.

In the present experiment, we added a group that would allow us to replicate the effect found by Clement et al. (2000) and to test the hypothesis that an FR1 schedule would be preferred over an FR30 schedule. For this group, no delay was added on FR1 trials. The procedure for this group differed somewhat from the procedure used by Clement et al. (2000). First, the high fixed ratio was increased from 20 pecks to 30 pecks. Second, to be able assess the schedule preference, choice trials started with the side keys illuminated (white), and the side key pecked determined the schedule that would be required on the center key, as in Experiment 1 . The center key schedule was further signaled by a stimulus (vertical or horizontal lines). Initially, to determine the pigeons' schedule preference, no simultaneous color discrimination followed the response requirement. Once we determined the schedule preference for each pigeon, we introduced a simultaneous color discrimination following completion of the initial response requirement (with or without a delay depending on the condition and trial type). Finally, as in Experiment 1, rather than train 20-plus sessions and then test as Clement et al. did, we included test sessions after 10-plus sessions and then after every 10 sessions thereafter, to better track the development of the within-trial contrast effect.

Although the contrast hypothesis does not predict which of the two schedules will be preferred, the FR30 or the FR1 with comparable delay, according to the contrast hypothesis, subjects should prefer the discriminative stimulus that follows the less preferred schedule because there should be a greater improvement in the value of the discriminative stimulus that predicts reinforcement. On the other hand, based on the delay reduction hypothesis alone, one would predict that when trial duration is held constant, there should be no differential preference for discriminative stimuli following the two schedules.

The purpose of Experiment 2 was to test the hypothesis that if trial duration was held constant, there still would be a preference for the discriminative stimulus that followed the least preferred schedule. A second purpose of this experiment was to compare the stimulus preference shown by Group Time-Same with that of Group Time-Different. For Group Time Different, there should be both a difference in delay reduction produced by the relative time of the appearance of the positive stimulus, as well as relatively greater contrast on high effort trials upon the appearance of the positive discriminative stimulus that followed the least preferred schedule. For Group Time-Same, there should be only the relatively greater 
contrast on high effort trials. Thus, if delay reduction also plays a role in this effect, Group Time-Different should show a greater preference for the positive discriminative stimulus that follows than Group Time-Same.

\section{Method}

Subjects-The subjects were 16 White Carneaux pigeons (Columba livia), retired breeders (5-8 years of age) of undetermined sex, purchased from the Palmetto Pigeon Plant (Sumter, SC) and were maintained under the same conditions as pigeons in Experiment 1. They had had previous experience in unrelated studies involving two-sample, two-alternative, matching-to-sample (conditional discriminations).

Apparatus-The experiment was conducted in the same apparatus as in Experiment 1. The two side keys projected red, green, blue and yellow colors (Kodak Wratten filters Nos. 26, 60,38 , and 9, respectively) as well as a white (unfiltered) stimulus. The center key projected three white parallel lines against a black background arranged either horizontally $(\mathrm{H})$ or vertically $(\mathrm{V})$. The three lines were $2.0 \mathrm{~mm}$ apart and each was $2.0 \mathrm{~mm}$ wide and $2.5 \mathrm{~cm}$ long. The experiment was controlled and data collected by a microcomputer located in an adjacent room.

\section{Procedure}

Schedule Preference Training: The pigeons were randomly assigned to one of two groups, Group Time-Different and Group Time-Same. All pigeons were pretrained to peck the center response key and the response requirement was gradually increased to 30 pecks (FR30). Training began on the following day. During the training phase, pigeons in both groups were exposed to two types of trial. For half of the pigeons in Group Time-Different, half of the trials began with a white stimulus presented on the left side key. One peck to the lit side key was followed by illumination of a vertical stimulus on the center key and a single peck to the vertical stimulus resulted in reinforcement. The remaining trials began with a white stimulus presented on the right side key. One peck to the right key was followed by illumination of a horizontal stimulus on the center key, but reinforcement was provided only after 30 pecks to the horizontal stimulus. The schedule initiated by the side key and the line orientation stimulus associated with that schedule were counterbalanced over pigeons.

For pigeons in Group Time-Same, the same two trial types occurred, but following the single peck on FR1 trials, the key light was turned off for a duration equal to the time required to make the remaining 29 pecks on the previous FR30 trial. Thus, the mean time as well as the distribution of times on FR1 and FR30 trials was the same. Following completion of each FR1 and FR30 trial, a 10-s intertrial interval followed during which the houselight was illuminated.

Each training session consisted of 72 trials, 36 FR1 trials alternating with 36 FR30 trials. Training sessions were conducted once a day, six days a week. All pigeons remained in schedule preference training for 30 sessions.

Schedule Preference Testing: During the first schedule preference testing phase, test trials were included in which the pigeons were given a choice between the left and right white side keys to determine their preference for the FR1 or FR30 schedules. On these trials, the schedule chosen was presented. These test trials were randomly interspersed among the training trials. Each session consisted of 72 trials (54 training trials and 18 schedule preference test trials). 
Pigeons remained in schedule preference testing for a minimum of 10 testing sessions. If at the end of 10 sessions a pigeon demonstrated a $90 \%$ preference or greater for one of the schedules, it was moved to the second testing phase. If the pigeon had not reached this $90 \%$ criterion within 10 sessions, it remained in the schedule preference testing phase until it had reached a stability criterion of 4 consecutive sessions in which the range of preference did not vary by more than $20 \%$.

Schedule Preference Testing 2 (reversal testing): To distinguish between a side preference and a schedule preference, all pigeons were given reversal testing in which the schedule signaled by each side key now signaled the other schedule.

Pigeons remained in reversal testing until they achieved a stability criterion of 4 sessions in which the range of preference did not vary by more than $20 \%$. Again, each session consisted of 72 trials (54 training trials and 18 test trials).

Discrimination Training: For both groups, during discrimination training, training trials were followed by presentation of pairs of discriminative stimuli. Each schedule was associated with a different pair of discriminative stimuli. For example, on FR30 trials, 30 pecks to the center key resulted in presentation of one pair of discriminative stimuli (e.g., red+ yellow-), one on the left key and the other on the right key (counterbalanced over trials). Choice of the positive stimulus (e.g., red) immediately resulted in reinforcement. For the pigeons in Group Time-Different, on FR1 trials, a single peck to the center key resulted in immediate presentation of a second pair of discriminative stimuli (e.g., green+ blue-), one on the left key and the other on the right key (counterbalanced over trials). Choice of the positive stimulus (i.e., green) resulted in reinforcement.

For the pigeons in Group Time-Same, pecking the center key resulted in a delay of equal duration to the time it took to complete the previous FR30 trial, followed by presentation of the second pair of discriminative stimuli (e.g., green+ blue-). Choice of the positive stimulus again resulted in reinforcement and a 10-s lit intertrial interval. Discriminative stimuli were counterbalanced such that half of the pigeons had red+ yellow- on FR30 trials and the other half of the pigeons had red+ yellow- on FR1 trials.

Each session consisted of 84 trials. There were 80 training trials, 40 FR 1 initiated trials and 40 FR30 initiated trials. The remaining 4 trials were choice trials on which pigeons were given a choice between the two schedules of reinforcement (i.e., the two white side keys were presented simultaneously) and whichever schedule was selected was obtained.

All pigeons remained in the training phase until they reached a criterion of $90 \%$ correct on both discriminations for two consecutive sessions.

Stimulus Preference Testing: The first test session was conducted after criterion had been reached in the discrimination training phase. Each test session included 48 test trials interspersed with 32 training trials. Half of the test trials involved a choice between the two positive stimuli (e.g., red and green). The remaining test trials involved a choice between the two negative stimuli (e.g., yellow and blue). Choice on all test trials was non-differentially reinforced, randomly $50 \%$ of the time.

It would have been most simple to present the two S+ stimuli or the two S- stimuli on test trials without a prior event, however, it could be argued that the absence of a prior event is more similar to the FR1 initial event than to the FR30 initial event. For this reason, for each group, in each session there were three kinds of S+ stimulus test trials and three kinds of Sstimulus test trials. For pigeons in both groups on one third of the test trials, the horizontal 
stimulus was presented on the center response key and 30 pecks (FR30) was required to turn it off and illuminate either the two S+ stimuli or the two S- stimuli from training. On another third of the test trials, no initial stimulus preceded either the two S+ stimuli or the two Sstimuli from training. On the remaining third of the test trials, for Group Time-Different, the vertical stimulus was presented on the center response key and one peck (FR1) was required to turn off the center key and illuminate two stimuli (either the two S+ stimuli or the two Sstimuli from training). However, on the remaining third of the test trials for Group TimeSame, the FR1 requirement to the vertical stimulus was followed by a delay (determined by the previous FR30 trial) prior to presentation of the two S+ or S- stimuli from training. Thus, the design was similar to the design of Experiment 1 with the exception that the DRO schedule was replaced by an FR1 schedule with an added delay to equate for trial duration on a trial by trial basis (see Figure 3). The test trials were randomly ordered and the two test stimuli were counterbalanced for side key presentation. Each of 6 test sessions was followed by an additional 10 sessions of training (except for the sixth and final test session).

\section{Results}

Schedule Preference-The last 4 sessions of Schedule Preference Testing Phases 1 and 2 were used to calculate schedule and side key preferences. If the schedule preference score was greater than the side preference score, the pigeon was judged to have a schedule preference.

There was a consistent schedule preference for pigeons in Group Time-Different. All 8 pigeons demonstrated a strong preference for the FR1 schedule. A Fisher's exact test (all $p$ 's $<.05$ ) showed that each of the pigeons demonstrated a significant schedule preference (see Table 2).

The pigeons in Group Time-Same, however, did not uniformly prefer the FR1 schedule. The majority of the pigeons $(n=6)$ showed a preference for the FR1 schedule, but one pigeon strongly preferred the FR30 schedule and one bird had a strong side preference (see Table 3). Although overall Group Time Different showed a greater preference (98.1\%) for the FR1 schedule than Group Same (77.9\%), because of the variability already mentioned the difference was not statistically significant, $t(14)=1.64, p=.12$. However, a Fisher's exact test showed that each pigeon demonstrated a significant schedule (or side) preference.

Discrimination Training-Pigeons took between 3 and 8 sessions to reach criterion on the two simultaneous discriminations $(M=4.2, S E M=.39)$. Pigeons in Group TimeDifferent learned the discrimination a bit faster $(M=3.67, S E M=.24)$ than pigeons in Group Time-Same $(M=4.9, S E M=.74)$, but this difference was not statistically significant, $F(1,15)=2.66, p>.05$.

Stimulus Preference Testing Group Time-Different-A schedule preference score was obtained for the first test session from the last 4 sessions of Schedule Preference Testing 1 and 2. For Test Sessions 2 through 6, the schedule preference score was calculated from the mean preference score from the preceding 10 sessions of training.

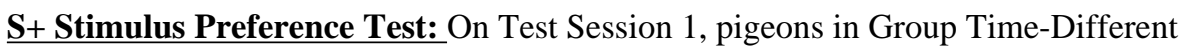
demonstrated a small preference for the $\mathrm{S}+$ stimulus associated with the FR30 trial type but the preference was not statistically significant, $t(7)=1.03, p>.05$. However, a stronger preference did develop by Test 3 and it remained stable across the remaining test sessions. A two-tailed $t$-test indicated that the preference was statistically significant on Test Sessions 3, 4,5 , and $6, t(7)=2.76,4.41,3.67,5.28$, respectively, all $p$ 's $<.05$. Figure 6 shows how this effect developed over the six testing sessions. 
If one considers only the FR30 and FR1 test trials (because those test trials are counterbalanced for the conditional stimulus effects of the prior event), when pooled over the test trials, there was a significant preference for the S+ stimulus that followed the FR30 initial event in training as well, $t(7)=2.86, p=.02$.

Examination of the correlation between the degree of schedule preference and the preference for the S+ stimulus that followed for pigeons in Group Time-Different indicated that the correlation was not statistically significant, $r=-.21, t<1$; however, the schedule preferences were all very strong $(>90 \%)$. When the correlation between the degree of schedule preference and the preference for the $\mathrm{S}+$ stimulus that followed was calculated for each test session the only significant correlation was on Test Session 4, $r=-.88, p=.002$.

S- Stimulus Preference Test: The preference for the S- stimulus associated with the FR30 trials was large and stable over all six testing sessions (see Figure 6). A two-tailed $t$-test indicated that this preference was statistically significant on Test $1, t(7)=3.99, p<.01$, Test $2, t(7)=3.10, p<.05$, Test $3, t(7)=2.62, p<.05$, and Test $5, t(7)=2.71, p<.05$. The preference was large, but not significant on Test $4, t(7)=2.08, p=.08$, and Test $6, t(7)=$ $2.04, p=.09$.

Considering only the FR30 and FR1 test trials, when pooled over the test trials, there was a significant preference for the S- stimulus that followed the FR30 initial event in training, $t(7)$ $=3.23, p=.01$.

Examination of the correlation between the degree of schedule preference and the preference for the S- stimulus that followed for pigeons in Group Time-Different indicated that the correlation was not statistically significant, $r=-.34, t<1$, but it was in the same negative direction as the correlation between the degree of schedule preference and the preference for the S+ stimulus that followed.

Effect of Initial Event on Test Trials: To determine if the initial event that occurred on the discriminative stimulus preference test affected choice of the discriminative stimulus, each test session was analyzed for choice of the FR30 stimuli preceded by the FR30, FR1, or no initial event (see Figure 7). The pigeons chose the FR30 stimulus more when it was preceded by an FR30 initiating event and chose the FR30 stimulus equally as often on FR1 and no initial event trials. Over all test sessions, there was a significant effect of initial event on choice of the $\mathrm{S}+$ stimulus, $F(2,15)=4.75, p<.05$ (see the left side of Figure 7).

Although the pigeons chose the S- stimulus associated with the FR30 event more often when preceded by the FR1 initial event than either the FR30 or no initial event, this difference was not statistically significant, $F(2,15)=2.68, p>.05$, (see the right side of Figure 7).

\section{Stimulus Preference Testing Group Time-Same}

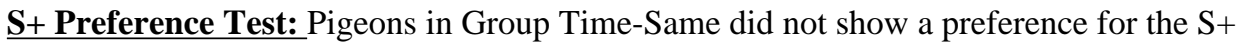
stimulus associated with their non-preferred schedule or side on Test Sessions 1, 2, or 3 (all $t$ s $<1$ ). However, a preference for the $\mathrm{S}+$ associated with the non-preferred event did develop by Test Session 4 and it remained stable on Test Sessions 5 and 6. Figure 8 shows how this contrast effect developed across test sessions for Group Time-Same. The preference was highest on Test Session $4(M=6.25 \%, S E M=3.15)$ but it was not statistically significant, $t(7)=1.99, p>.05$, because of the variability in preferences among the pigeons. On the other hand, pigeons in Group Time-Same chose the $\mathrm{S}+$ associated with the non-preferred event significantly above chance on Test Session 5, $t(7)=3.03, p=.02$, and on Test Session 6, $t(7)=2.99, p=.02$. 
Considering only the FR30 and FR1 test trials, when pooled over the test trials, there was a significant preference for the S+ stimulus that followed the FR30 initial event in training, $t(7)=3.37, p=.01$.

Examination of the correlation between the degree of schedule preference and the preference for the S+ stimulus that followed for pigeons in Group Time-Same pooled over testing sessions indicated that the correlation was not statistically significant, $r=-.50, t<1$, however, once again, the schedule preferences were all very strong $(>86 \%)$. When the correlation between the degree of schedule preference and the preference for the $\mathrm{S}+$ stimulus that followed was calculated for each test session the only significant correlation was on Test Session 5, $r=-.89, \mathrm{p}=.003$.

S- Preference Test: Similar stimulus preference tests were conducted for the S- stimuli. They indicated that the negative stimulus associated with the non-preferred schedule (or side) was not significantly preferred on any of the 6 test sessions. As shown in Figure 8, preference for the S- stimulus associated with the non-preferred schedule (or side) decreased across test sessions.

Considering only the FR30 and FR1 test trials, when pooled over the test trials, there was not a significant preference for the S- stimulus that followed the FR30 initial event in training, $t(7)=1.24, p=.26$.

Examination of the correlation between the degree of schedule preference and the preference for the S- stimulus that followed for pigeons in Group Time-Same indicated that the correlation was not statistically significant, $r=-.34, t<1$.

Effect of Initial Event on Test Trials: On S+ test trials, pigeons in Group Time-Same chose the FR30 stimulus more often when the initial event on a test trial was the FR30 event than when it was either the FR1 or no initial event. However, this effect was not statistically significant, $F(2,15)=2.46, p>.05$ (see Figure 9).

On S- test trials, pigeons in Group Time-Same chose the negative stimulus associated with the FR30 event significantly more often when it was preceded by no initial event than when it was preceded by either the FR1 or FR30 initial event, $F(2,15)=5.56, p<.05$.

\section{Group Comparisons}

Stimulus Preference Comparisons: To more directly compare the development of the of the preference for the S+ stimulus following the least preferred schedule for the two groups, the $\mathrm{S}+$ choice trial data for the two groups have been plotted in Figure 10. As can be seen in Figure 10, the preference for the S+ stimulus following the least preferred schedule appeared to be somewhat greater for pigeons in Group Time-Different than for pigeons in Group Time-Same.

A two-way mixed model analysis of variance was conducted to compare the preference for the stimuli following the least preferred schedule in Group Time-Same and Group TimeDifferent as a function of the test session. The analysis indicated that the effect of Test Session was significant, $F(5,75)=4.55, p<.001$; however, the effect of Group was not significant, $F<1$, and neither was the Group $\times$ Test Session interaction, $F(5,75)=1.37, p$ $>.05$. The preference for the $\mathrm{S}+$ that was preceded by the least preferred schedule was significantly greater for pigeons in Group Time Different only on Test Session 3, $F(1,15)=$ $4.54, p=.05$. Pigeons in Group Time-Different chose the $\mathrm{S}+$ associated with the FR30 event $60.4 \%$ and pigeons in Group Time-Same chose the S+ associated with their non-preferred schedule or side only $49.5 \%$ of the time. Thus, the advantage in $\mathrm{S}+$ preference associated 
with the difference in the duration of the initial events for Group Time Different was not very great.

\section{Discussion}

The significant preferences for the FR1 schedule shown by pigeons in Group Time-Different are consistent with the law of least effort which predicts that when given a choice, pigeons will prefer to do less work (or receive reinforcement more quickly); however, they are also consistent with delay reduction theory. Friedrich and Zentall (2004) found similar results.

The results for Group Time-Same suggest that although there was not a systematic preference among pigeons, six of the eight pigeons did prefer the FR1 plus delay over the FR30, and the remaining two pigeons did have a strong preference (one for the FR30 schedule and the other for one side key). Thus, for six of the eight pigeons less pecking was preferred over more pecking even when delay to reinforcement was controlled.

Following simultaneous discrimination training, pigeons in Group Time-Different demonstrated a significant preference for the positive discriminative stimulus that followed the nonpreferred FR30 schedule during training. This result is consistent with both the contrast hypothesis and delay reduction theory. To differentiate between the contrast and delay reduction accounts, pigeons in Group Time-Same were tested under conditions in which the delay to reinforcement was held constant for the two trial types. Consistent with the contrast account, the pigeons in Group Time-Same demonstrated a significant preference for the positive discriminative stimulus that followed the nonpreferred schedule (or side).

Thus, the results of the Experiment 2 suggest that although delay reduction may contribute to the preference for an S+ stimulus that follows a less preferred event in several of the published studies, it is insufficient to account for the results of the $\mathrm{S}+$ stimulus preference found for Group Time Same in the present study. Furthermore, differences in the preference for the least preferred initial event between Group Time Different and Group Time Same may also have resulted in greater contrast for Group Time Different than for Group Time Same (for Group Time Different there was a stronger preference for FR1 trials than for FR30 trials). And if the initial events for the two groups were differentially preferred, the resulting differential contrast could have accounted for the differences between the two groups in their preference for the S+ stimulus that followed the least preferred event. Therefore, contrast may not only account for the FR30 S+ preference for Group Time Same but it may also account for the difference in FR30 S+ preference between Group Time Different and Group Time Same.

In most of the experiments in the present line of research, each initial event was followed by a simultaneous discrimination, rather than a single stimulus (followed by reinforcement), to reduce the likelihood of a disruption of performance produced by the novelty of the choice on test trials. That is, if the pigeons were required to choose between the S+ and S- stimuli during training it was thought that requiring them to make a choice (between the two $\mathrm{S}+$ stimuli) on test trials would be less novel and thus less disruptive. Although, within-trial contrast makes specific predictions about the value of the $\mathrm{S}+$ stimulus that follows a relatively aversive event, it makes no prediction about the value of the accompanying $\mathrm{S}$ stimulus. However, having trained with two S- stimuli allowed us to track the fate of the two S- stimuli.

The pigeons in Group Time Different did show a preference for the S- that followed the nonpreferred FR30 schedule during training, however, the pigeons in Group Time Same did not. The failure to find an effect in preference for the S- stimuli is consistent with several previous studies that have also failed to find such an effect (see DiGian, et al., 2004 and 
Friedrich, et al., 2005 but see Clement et al., 2000 for results similar to those found for Group Time Different).

There also was an effect of the initial event on test trials on choice of the S+ and S-stimuli associated with the non-preferred event for pigeons in both groups. Pigeons chose the FR30 S+ stimulus more often when it was preceded by an FR30 initial event on a test trial than when it was preceded by an FR1 or no initial event. This suggests that to some extent the initial event on test trials acted like a conditional stimulus, preparing the pigeon to choose the $\mathrm{S}+$ stimulus, in spite of the fact that in training the correct response could be made to the $\mathrm{S}+$ stimulus without regard to the initial event.

However, in spite of the conditional stimulus effect on FR30 test trials, overall on test trials, pigeons showed a significant preference for the $\mathrm{S}+$ stimulus associated with the FR30 schedule during training. Had the entire effect on test trials been produced by the conditional choice of the S+ stimuli, choice of the FR30 S+ on test trials initiated by the FR1 event should have been (symmetrically) below chance. That is, because there was an equal number of FR1 and FR30 initial event test trials, had the S+ stimulus preference been solely conditional, the net preference for the FR30 S+ stimulus (the combined preference for the FR30 S+ when preceded by an FR30 event and an FR1 event) should have been 50\%. Furthermore, in previous research that has investigated the effect of a prior event on discriminative stimulus preference, conditional effects of the initial event during testing typically have not been found (see Experiment1 of the present study; Clement et al., 2000; DiGian et al., 2004; Friedrich et al., 2005; Friedrich \& Zentall, 2004).

A different pattern of results emerged for the effect of the initial event on choice of the Sstimulus. In this case, more choices of the FR30 S- occurred after the FR1 initial event for pigeons in Group Time-Different. This effect is similar to the effect found in schedule preference testing, in which pigeons appeared to be using the initial event as a conditional stimulus to avoid the S- stimulus that followed (see Arantes \& Grace, 2008 for a similar effect). Although a similar preference for the FR30 S- stimulus on test trials with an initial FR1 event was not found for pigeons in Group Time-Same, stimulus preferences associated with the S- stimuli generally have been less consistent over studies. The reason for the inconsistencies in the preference for the S-stimulus may be related to the fact that responding to the negative discriminative stimuli occurs primarily early in training and given the large amount of over training required to observe the effect of the prior initial event on the $\mathrm{S}+$ stimulus during training, as noted earlier, during test sessions the pigeons would have had little recent experience with the consequences of responding to the Sstimuli.

In the present experiment, pigeons demonstrated a significant preference for the $\mathrm{S}+$ stimulus that followed their non-preferred schedule or side. Unlike Clement et al. (2000), in the current experiment, the effect was slow to develop but there was a regular increase over testing sessions. In previous studies of within-trial contrast, once the simultaneous discriminations were learned, pigeons were given 20 overtraining sessions and then were given a single test session or a series of test sessions with probe test trials mixed with training trials. In the current experiment, pigeons were tested using probe test sessions. The pigeons were first tested immediately after reaching criterion on the simultaneous discrimination task to get a stimulus preference baseline. All subsequent test sessions were each preceded by 10 additional training sessions. This procedure allowed us to examine the development of the contrast effect over sessions.

The relatively slow development of the within-trial contrast effect may account for the failure to observe such an effect by Vasconcelos et al. (2007). Although 20 sessions of 
overtraining were sufficient for the within-trial contrast effect to develop for Clement et al. (2000), 20 sessions were not sufficient in the present experiments (see also Friedrich et al., 2005; Friedrich \& Zentall, 2004; Singer et al., 2007). When Vasconcelos and Urcuioli (2008) gave pigeons more than 20 overtraining sessions, they found a preference of more than $60 \%$ for the S+ stimulus that in training followed the nonpreferred (FR30) schedule, but because of the low power of their study (they had only four pigeons in their study, only three of which could be tested) the preference was not statistically reliable.

Another factor that may be important in observing the within-trial contrast effect is the preexperimental experience that the pigeons have had. Arantes and Grace (2008) found that they were unable to replicate the effect reported by Clement et al. (2000) even when their pigeons were trained considerably longer than 20 sessions; however, unlike the pigeons in the present experiments which had experienced relatively rich schedules of reinforcement prior to serving in the present experiment (discrete trial conditional discriminations), Arantes and Grace's pigeons had had considerable experience with lean variable-interval schedules. It may be that the prior exposure to lean schedules experienced by Arantes and Grace's pigeons reduced the contrast between the FR30 schedule and the simultaneous discrimination. In any event, although the effects of within trial contrast appear to occur under a wide variety of conditions as documented in the introduction, it is of interest to know under what conditions they do not occur and for both theoretical and practical reasons, those conditions are worthy of further study.

\section{General Discussion}

The results of Experiments 1 and 2, together with the results of Singer et al. (2007), indicate that the within-trial contrast effect found here and in earlier research cannot be accounted for solely by appealing to relative delay reduction. Instead it appears that a contrast-like process is involved. We suggest that within-trial contrast can serve that role. Within-trial contrast occurs when the value of an event is judge relative to the event that preceded it. Thus, greater effort, greater hunger, a longer wait, or the absence of food can provide greater value to a discriminative stimulus (that is followed by food) than a different discriminative stimulus (followed by the same food) that was preceded by less effort, less hunger, a shorter wait, or food.

The within-trial contrast effect reported here and in earlier experiments may be related to the sunk-cost effect reported in pigeons (Navarro \& Fantino, 2005; Pattison, Zentall, \& Watanabe, in press). For example, Pattison et al. found that pigeons that made an initial investment in pecking a stimulus often chose to peck a stimulus of the same color to complete the pecking requirement, rather than peck a different color, even if switching to the other color meant that they would have to make fewer pecks. In the case of sunk cost, unlike within-trial contrast, choice of the color of the stimulus that matched the initial investment actually incurred an additional cost.

In traditional human research, preferences such as those reported here would typically be attributed to cognitive factors, such as cognitive dissonance (Festinger, 1957) or more specifically to a form of cognitive dissonance called justification of effort (Aronson \& Mills, 1959). However, it is possible that within-trial contrast can also explain justification of effort results when reported in humans. That is, within-trial contrast may explain why humans appear to value reinforcers more if they have to work hard to obtain them or why they value joining groups for which they have to experience more severe initiation to join. For example, Aronson and Mills (1959) had students undergo a "severe" or a "mild" initiation to join in a discussion group. Subjects in the severe initiation group were required to read a sexually explicit passage out loud in front of the experimenter, whereas those in the mild 
initiation group read a less embarrassing passage. When the subjects were asked to evaluate the discussion group, those in the severe initiation condition rated it higher than those in the mild initiation group. Aronson and Mills interpreted their result in terms of cognitive dissonance. According to Aronson and Mills, to resolve the dissonance produced by reading the embarrassing passage, subjects in the severe initiation group gave more value to the discussion group than did subjects in the mild initiation group. In more general terms, the more difficult the task, the greater the value given to the reinforcers that follow task completion to justify having participated in the difficult task.

Alternatively, contrast between the less preferred difficult task and the positive value of reinforcer (joining the group) may have enhanced the value of the reinforcer by way of contrast. Consistent with this hypothesis, evidence for within-trial contrast of the kind first described by Clement et al. (2000) has been found in humans, both children (Alessandri, Darcheville, \& Zentall, 2008) and adults (Alessandri, Darcheville, Delevoye-Turrell, \& Zentall, 2008; Klein, Bhatt \& Zentall, 2005). Thus, it may be that the kind of within-trial contrast effects examined in the present research and earlier studies has generality beyond these experiments with pigeons and may be applicable to a broader range of human social psychological phenomena.

\section{Acknowledgments}

This research was supported by National Institute of Mental Health Grant MH63726 and by National Institute of Child Health and Development Grant HD60996 to T.R.Z. and by National Research Service Award Grant MH77450 to R.A.S.

\section{References}

Alessandri J, Darcheville J-C, Delevoye-Turrell Y, Zentall TR. Preference for rewards that follow greater effort and greater delay. Learning \& Behavior. 2008; 36:352-358. [PubMed: 18927058]

Alessandri J, Darcheville J-C, Zentall TR. Cognitive Dissonance in Children: Justification of Effort or Contrast? Psychonomic Bulletin \& Review. 2008; 15:673-677. [PubMed: 18567273]

Arantes J, Grace RC. Failure to obtain value enhancement by within-trial contrast in simultaneous and successive discriminations. Learning \& Behavior. 2008; 36:1-11. [PubMed: 18318421]

Aronson E, Mills J. The effects of severity of initiation on liking for a group. Journal of Abnormal and Social Psychology. 1959; 59:177-181.

Clement TS, Feltus JR, Kaiser DH, Zentall TR. 'Work Ethic' in pigeons: Reward value is directly related to the effort or time required to obtain the reward. Psychonomic Bulletin and Review. 2000; 7:100-106. [PubMed: 10780022]

Clement TS, Zentall TR. Second-order contrast based on the expectation of effort and reinforcement. Journal of Experimental Psychology: Animal Behavior Processes. 2002; 28:64-74. [PubMed: 11868235]

DiGian KA, Friedrich AM, Zentall TR. Discriminative stimuli that follow a delay have added value for pigeons. Psychonomic Bulletin and Review. 2004; 11:889-895. [PubMed: 15732699]

Fantino E, Abarca N. Choice, optimal foraging, and the delay-reduction hypothesis. The Behavioral and Brain Sciences. 1985; 8:315-330.

Fantino E. Choice and rate of reinforcement. Journal of Experimental Analysis of Behavior. 1969; 12:723-730.

Fersen, Lv; Wynne, CDL.; Delius, JD.; Staddon, JER. Transitive inference formation in pigeons. Journal of Experimental Psychology: Animal Behavior Processes. 1991; 17:334-341.

Festinger, L. A theory of cognitive dissonance. Stanford, CA: Stanford University Press; 1957.

Friedrich AM, Clement TS, Zentall TR. Discriminative stimuli that follow the absence of reinforcement are preferred by pigeons over those that follow reinforcement. Learning and Behavior. 2005; 33:337-342. [PubMed: 16396080] 
Friedrich AM, Zentall TR. Pigeons shift their preference toward locations of food that take more effort to obtain. Behavioural Processes. 2004; 67:405-415. [PubMed: 15518990]

Grace R. A contextual model of concurrent-chains choice. Journal of the Experimental Analysis of Behavior. 1994; 61:133-129.

Hull, CL. Principles of behavior. New York: Appleton-Century-Crofts; 1943.

Johnson AW, Gallagher M. Greater effort boosts the affective taste properties of food. Proceedings of the Royal Society B: Biological Sciences. 2011; 278:1450-1456.

Kacelnik A, Marsh B. Cost can increase preference in starlings. Animal Behaviour. 2002; 63:245-250.

Klein ED, Bhatt RS, Zentall TR. Contrast and the justification of effort. Psychonomic Bulletin and Review. 2005; 12:335-339. [PubMed: 16082815]

Marsh B, Schuck-Paim C, Kacelnik A. Energetic state during learning affects foraging choices in starlings. Behavioral Ecology. 2004; 15:396-399.

Mazur JE. Hyperbolic value addition and general models of animal choice. Psychological Review. 2001; 108:96-112. [PubMed: 11212635]

Pompilio L, Kacelnik A, Behmer ST. State-dependent learned valuation drives choice in an invertebrate. Science. 2006 Mar 17.311:1613-1615. [PubMed: 16543461]

Revusky SH. Hunger level during food consumption: Effects on subsequent preference. Psychonomic Science. 1967; 7:109-110.

Singer RA, Berry LM, Zentall TR. Preference for a stimulus that follows an aversive event: Contrast or delay reduction? Journal of the Experimental Analysis of Behavior. 2007; 87:275-285. [PubMed: 17465316]

Spence KW. The differential response of animals to stimuli differing within a single dimension. Psychological Review. 1937; 44:430-444.

Spetch ML, Wilkie DM, Pinel JP. Backward conditioning: A reevaluation of the empirical evidence. Psychological Bulletin. 1981; 89:163-175. [PubMed: 7232608]

Vasconcelos M, Urcuioli PJ. Deprivation level and choice in pigeons: A test of within-trial contrast. Learning \& Behavior. 2008; 36:12-18. [PubMed: 18318422]

Vasconcelos M, Urcuioli PJ, Lionello-DeNolf KM. Failure to replicate the "work ethic" effect in pigeons. Journal of the Experimental Analysis of Behavior. 2007; 87:383-399. [PubMed: 17575903]

Zentall TR, Sherburne LM. Transfer of value from S+ to S- in a simultaneous discrimination. Journal of Experimental Psychology: Animal Behavior Processes. 1994; 20:176-183. [PubMed: 8189186] 


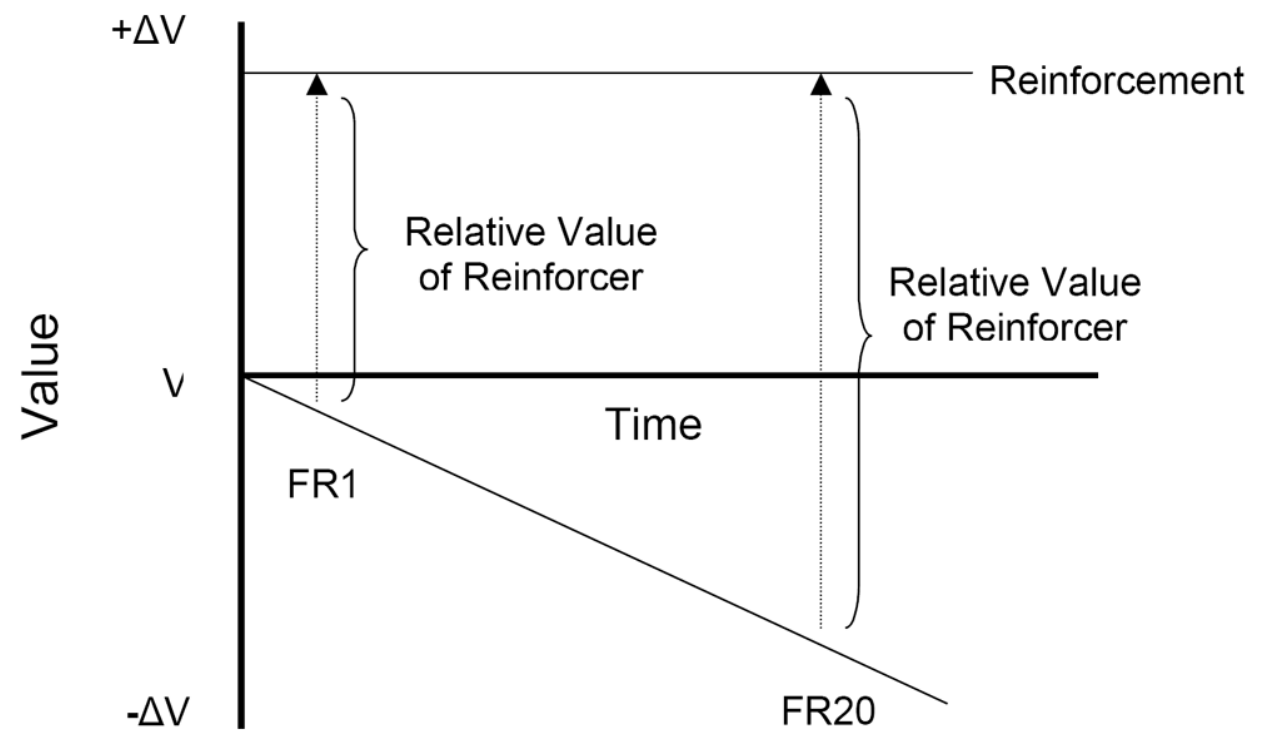

Figure 1.

Model of within-trial contrast based on relative value. Each trial begins at state V.

Keypecking (or other nonpreferred event such as delay) causes a negative change in value and reinforcement results in a positive change in value. The FR20 response requirement results in a relatively more negative state than the FR1 requirement ( $\mathrm{V}-\Delta \mathrm{V}_{\mathrm{FR} 20}$ and $\mathrm{V}$ $\Delta \mathrm{V}_{\mathrm{FR} 1}$, respectively) and hence in a greater positive change in value upon obtaining the reinforcer (or the discriminative stimulus associated with reinforcement; adapted from Zentall, 2005). 

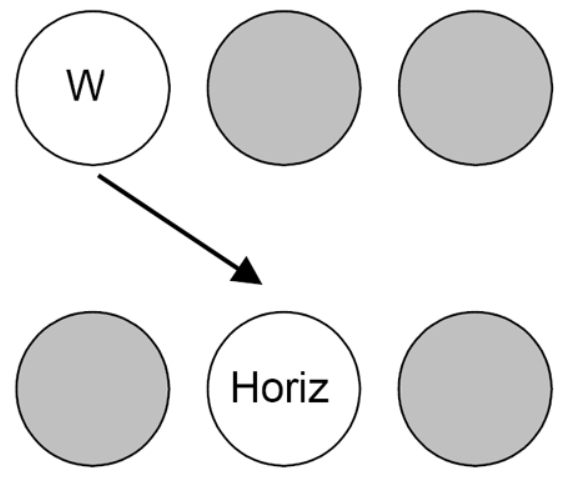

DRO

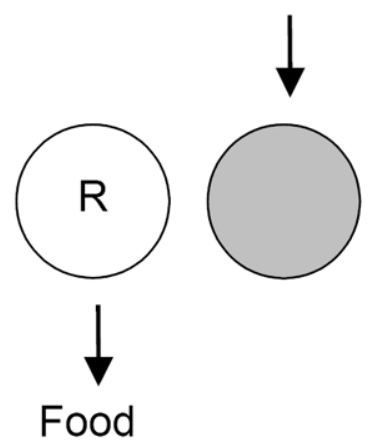

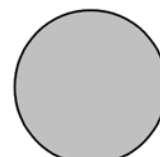
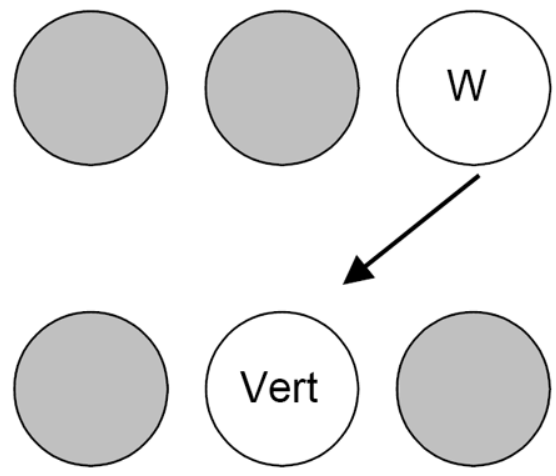

FR

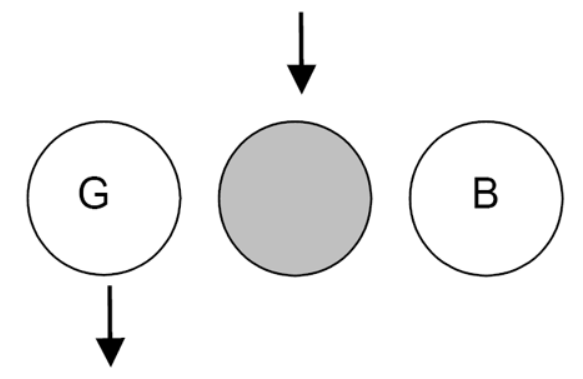

Food

Figure 2.

Design of Experiment 1: discrimination training for one counterbalancing condition. Left panel shows the discrimination made after DRO trials and the right panel shows the discrimination that had to be made following FR trials. 

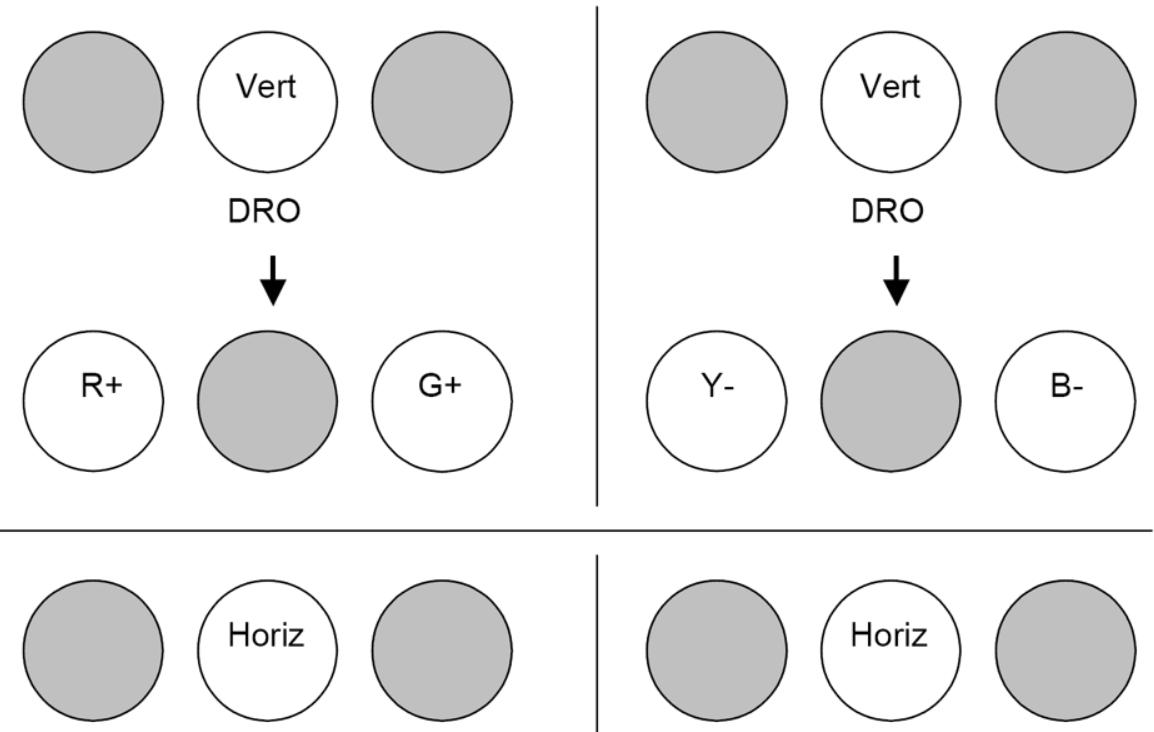

FR20

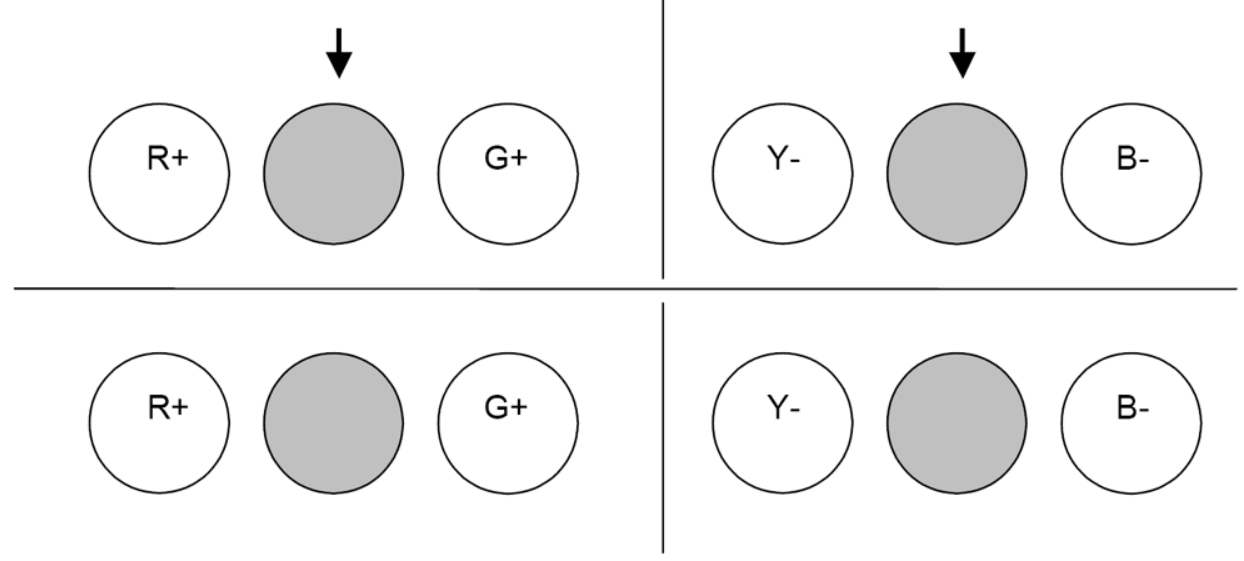

Figure 3.

Experiment 1: Test trials: The six trial types are presented with DRO initiated trials shown in the top panel, FR20 initiated trials shown in the middle panel, and trials with no prior stimulus shown in the bottom panel. Half of the trials involve presentation of both positive stimuli (i.e., red and green) and are shown on the left side of the figure. The remaining trials involve presentation of the two negative stimuli (i.e., yellow and blue) and are shown on the right side of the figure. 


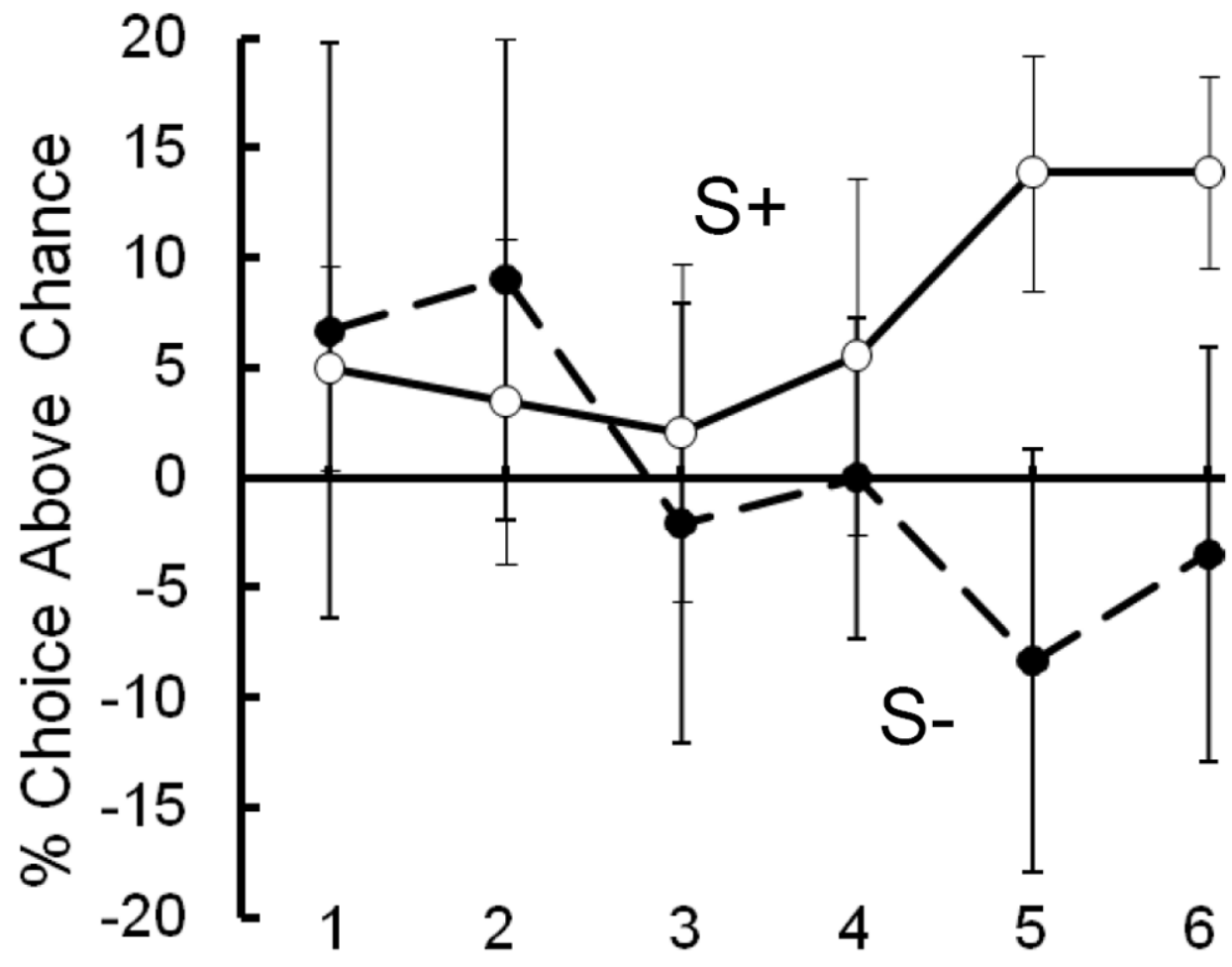

\section{Test Session}

Figure 4.

Experiment 1: Preference for the S+ that followed the less preferred schedule or side over the six testing sessions in (solid lines, open circles) and preference for the S- that followed the less preferred schedule or side over the six testing sessions (dashed lines, filled circles). 


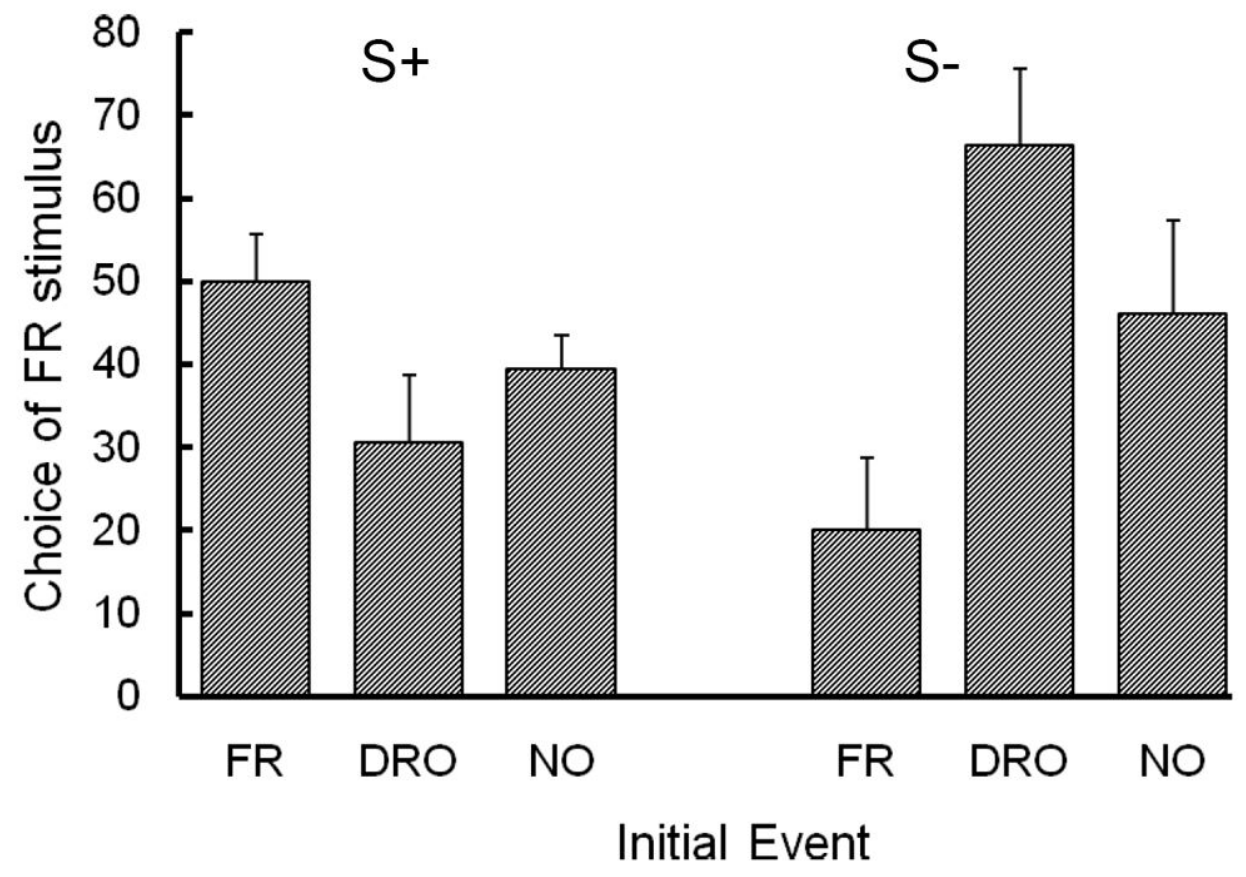

Figure 5.

Experiment 1: Effect of initial event (20 pecks required, FR20, refraining from pecking DRO, or no initial event, NO) on choice of the FR S+ and S- over all six testing sessions in Experiment 1. 


\section{Group Time-Different}

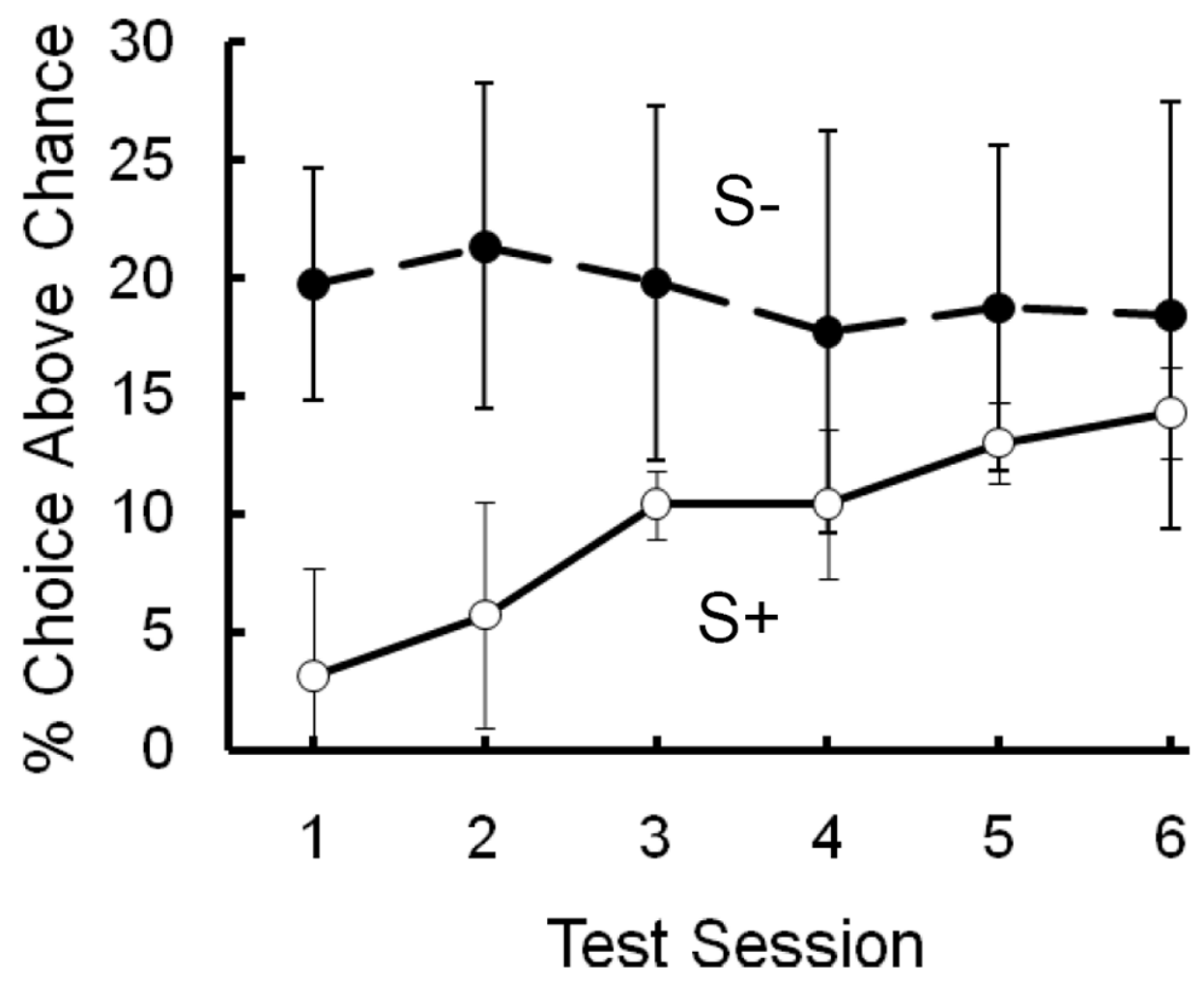

Figure 6.

Experiment 2: Group Time-Different: Preference for the S+ stimulus (solid lines, open circles) and for the $\mathrm{S}$ - stimulus (dashed lines, filled circles) that followed the FR30 trial type in training. Error bars represent \pm 1 standard error of the mean. 


\section{Group Time-Different}

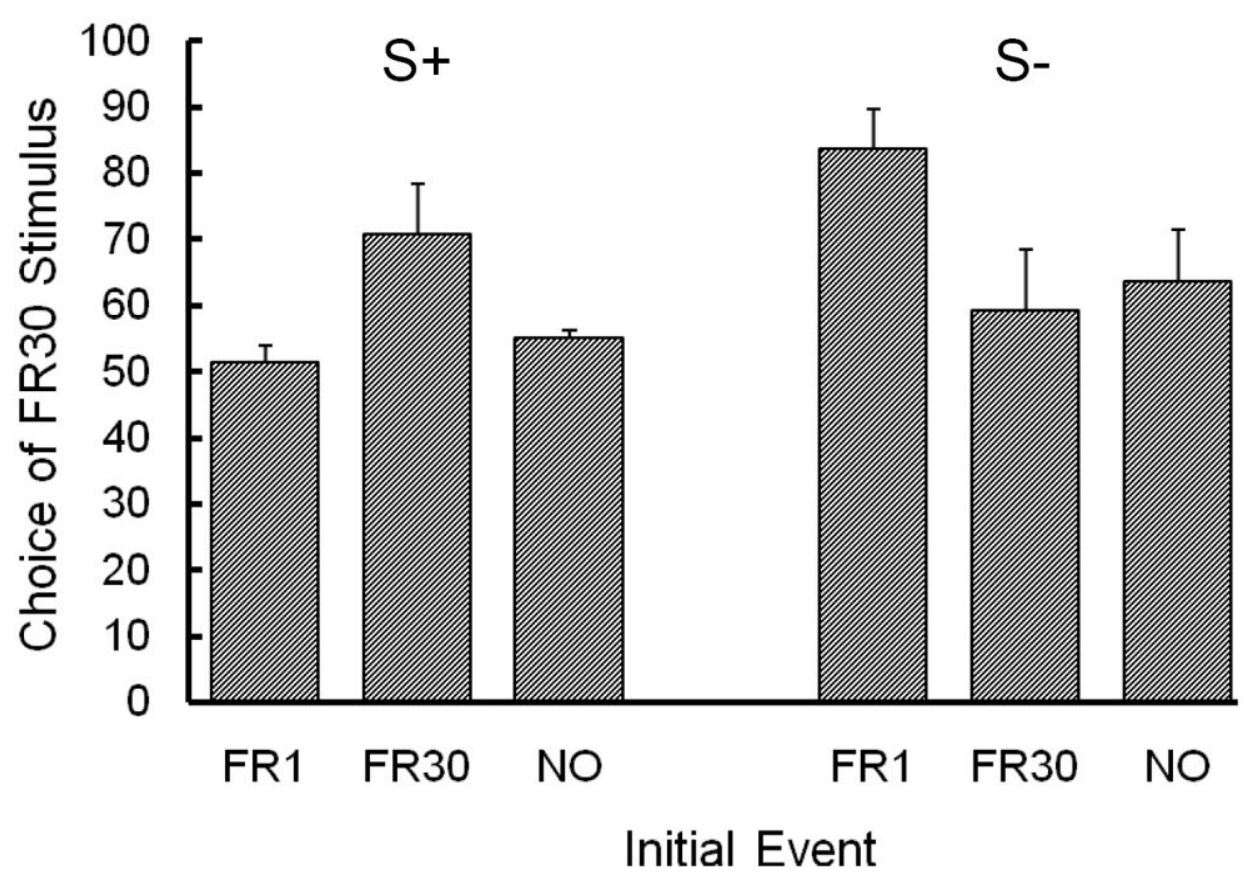

Figure 7.

Experiment 2: Group Time-Different: Effect of the initial event (1 peck required, FR1, 30 pecks required, FR30, or no initial event, NO) on choice of the FR30 S+ and S- stimulus for the six test sessions. Error bars represent \pm 1 standard error of the mean. 


\section{Group Time-Same}

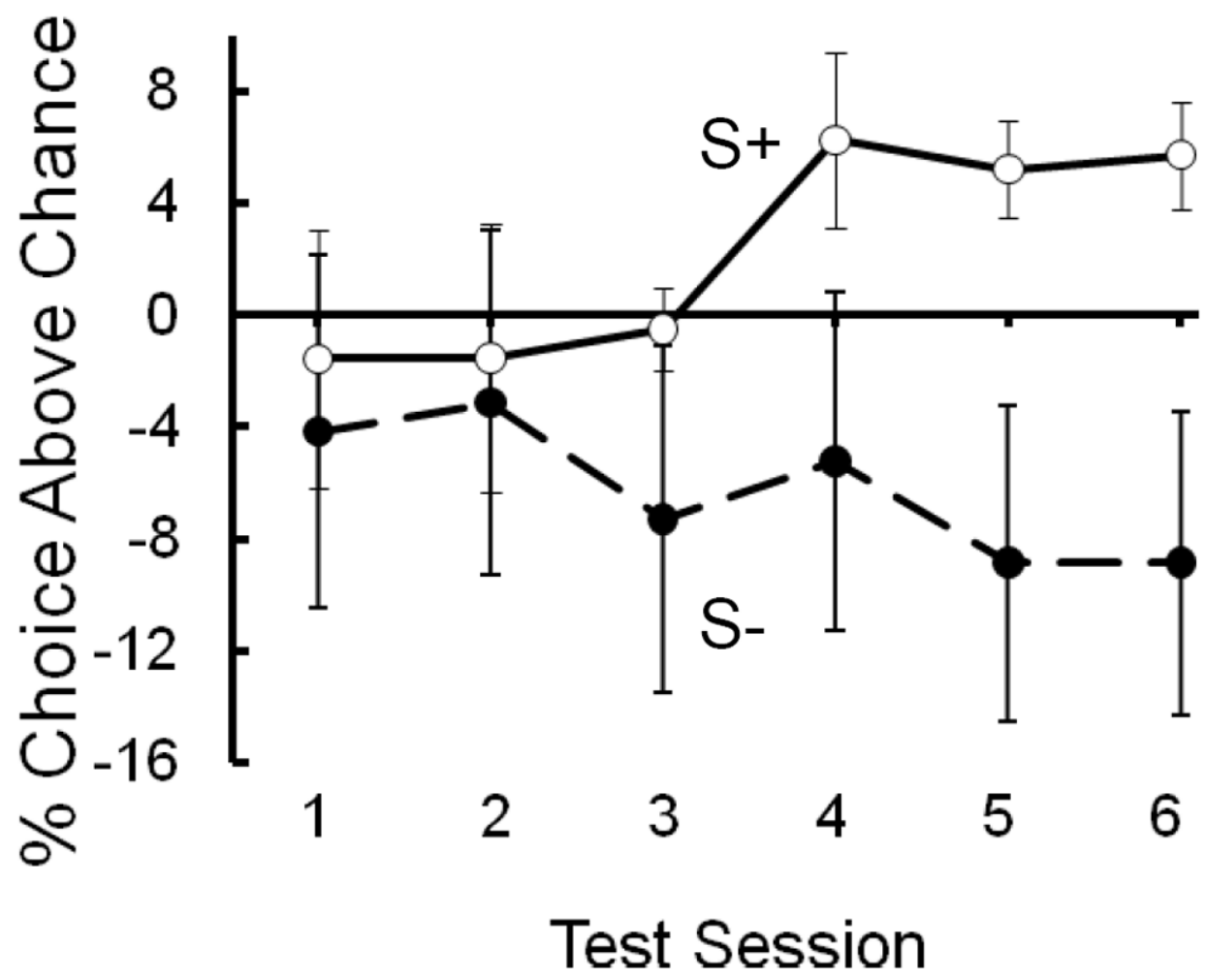

Figure 8.

Experiment 2: Group Time-Same: Preference for the S+ stimulus (solid lines, open circles) and for the S- stimulus (dashed lines, filled circles) that followed the FR30 trial type in training. Error bars represent \pm 1 standard error of the mean. 


\section{Group Time-Same}

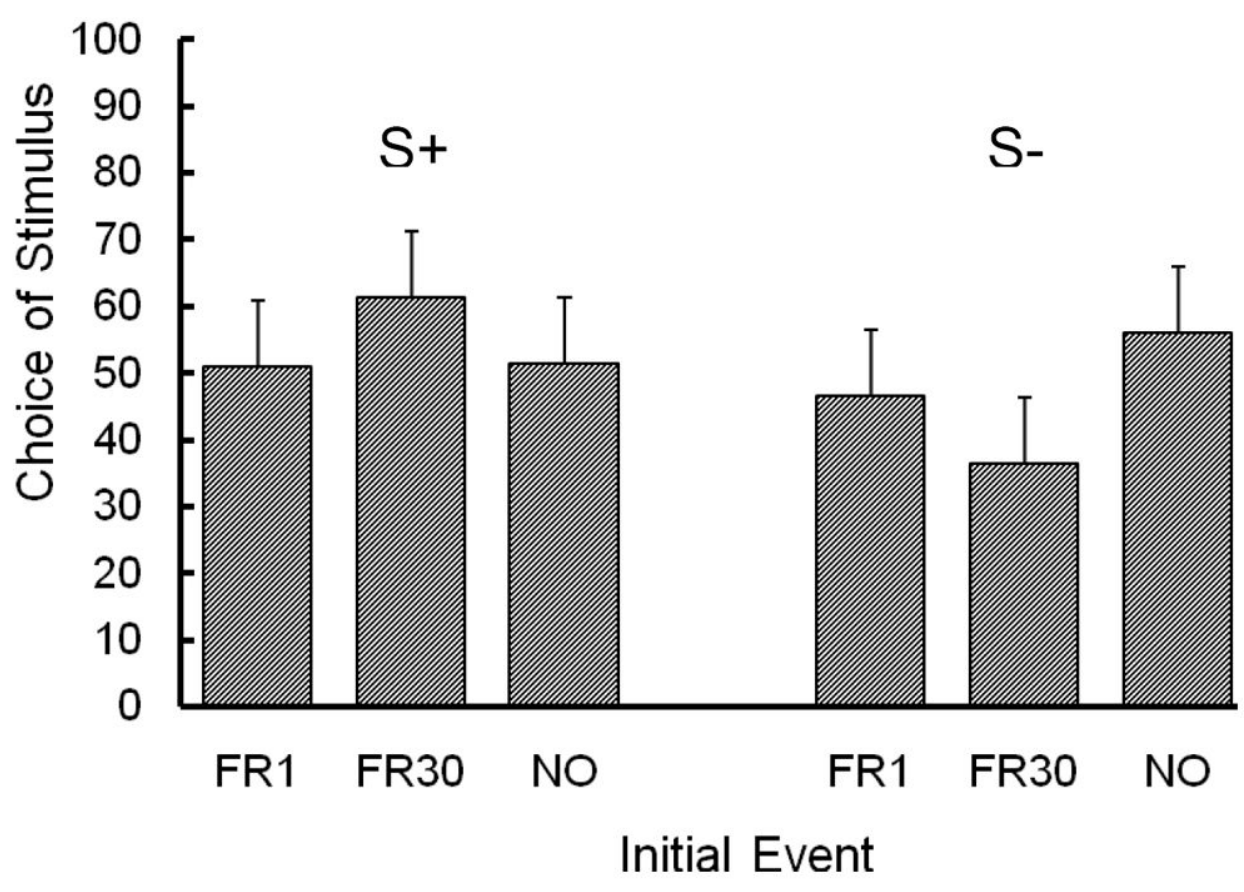

Figure 9.

Experiment 2: Group Time-Same: Effect of the initial event (1 peck required, FR1, 30 pecks required, FR30, or no initial event, NO) on choice of the FR30 S+ and S-stimulus for the six test sessions. For all of the pigeons the data are plotted in terms of the preference for the stimulus that followed the least preferred initial event: for 6 pigeons it was FR30, for 1 pigeon it was FR1, and for the remaining pigeon it was a side preference (all indicated as stimulus preference). Error bars represent \pm 1 standard error of the mean. 


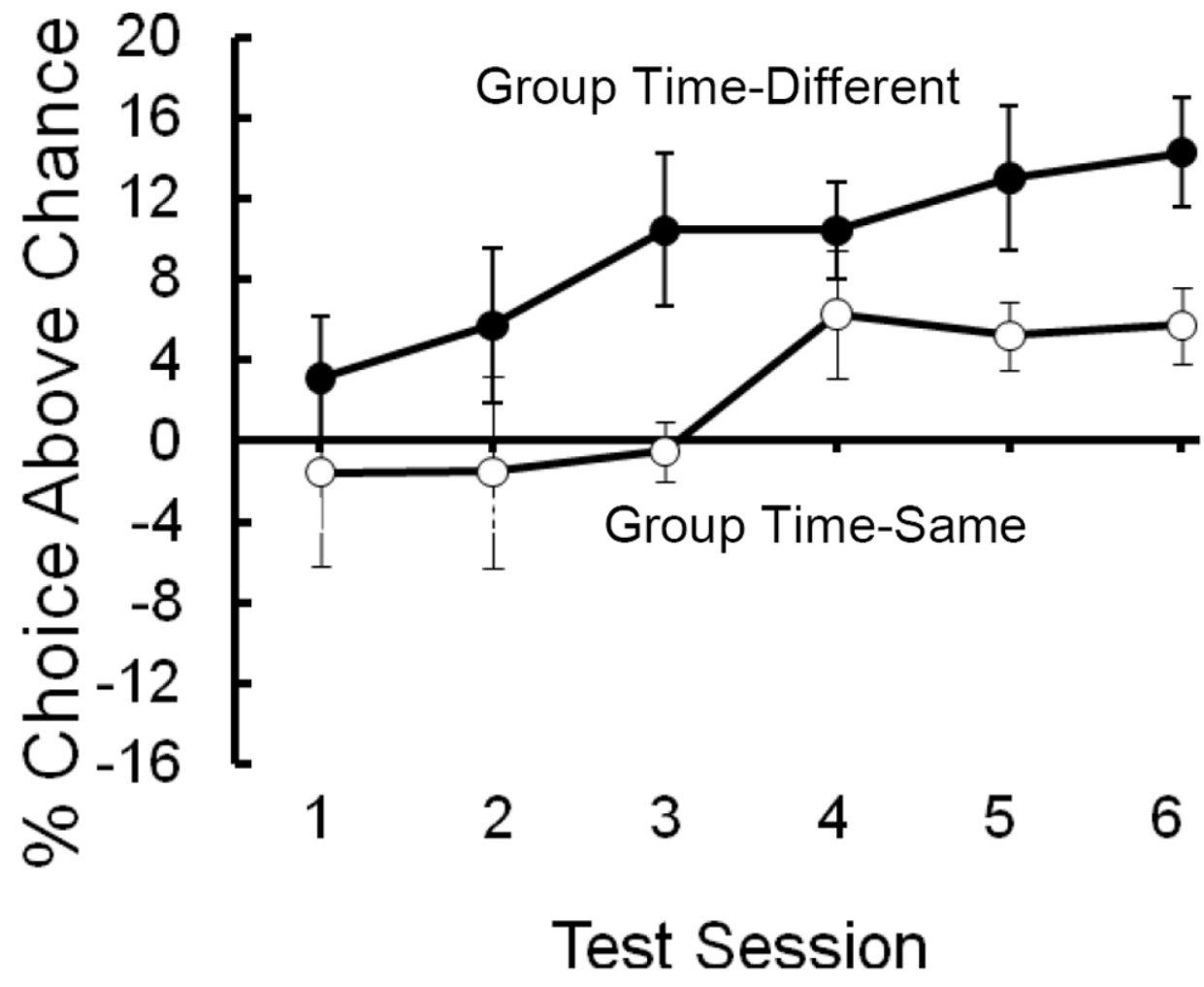

Figure 10.

Experiment 2: Comparison of preference for the $\mathrm{S}+$ stimulus that followed the FR30 trial type in training for Group Time-Same (open circles) and Group Time Different (filled circles). Error bars represent \pm 1 standard error of the mean. 


\section{Table 1}

Experiment 1: Schedule and side preference results.

\begin{tabular}{rllc}
\hline Pigeon \# & Schedule Preference & Side Preference & Net Preference \\
\hline 6640 & 40.98 & $90.97^{*}$ & side \\
10378 & 40.97 & $81.24^{*}$ & side \\
4920 & $99.31^{*}$ & 49.31 & DRO \\
5131 & $78.47^{*}$ & 43.75 & FR \\
9606 & $96.53 *$ & 46.53 & DRO \\
9055 & $88.89^{*}$ & 48.61 & DRO \\
8913 & 48.61 & $95.83^{*}$ & side \\
\hline$*$ &
\end{tabular}


Table 2

Experiment 2: Schedule and side preferences results for Group Time-Different.

\begin{tabular}{llcc}
\hline Pigeon \# & Schedule Preference & Side Preference & Net Preference \\
\hline 5560 & $99.31^{*}$ & 50.70 & FR1 \\
1598 & $98.61^{*}$ & 51.39 & FR1 \\
884 & $100^{*}$ & 50.00 & FR1 \\
3904 & $98.74^{*}$ & 56.95 & FR1 \\
4278 & $93.06^{*}$ & 51.39 & FR1 \\
10199 & $98.61^{*}$ & 52.78 & FR1 \\
8784 & $97.22^{*}$ & 50.70 & FR1 \\
4790 & $99.31^{*}$ & 50.00 & FR1 \\
\hline
\end{tabular}

Significantly different from chance, $p<.05$ 
Table 3

Experiment 2: Schedule and side preference results for Group Time-Same.

\begin{tabular}{llcl}
\hline Pigeon \# & Schedule Preference & Side Preference & Net Preference \\
\hline 6029 & $100.00^{*}$ & 50.00 & FR30 \\
6056 & $98.61^{*}$ & 50.00 & FR1 \\
10053 & 54.18 & $93.04^{*}$ & side \\
10006 & $98.61^{*}$ & 51.39 & FR1 \\
10552 & $96.53^{*}$ & 53.48 & FR1 \\
2219 & $86.81^{*}$ & 63.19 & FR1 \\
6605 & $90.28^{*}$ & 55.55 & FR1 \\
8797 & $97.92^{*}$ & 52.09 & FR1 \\
\hline
\end{tabular}

Significantly different from chance, $p<.05$ 